\title{
STATISTICAL THIRD-PARTY ORDER PROCESSING (STPOP) FOR QUICK CUSTOMER INVOICING
}

\author{
Arvind Kumar ${ }^{1}$

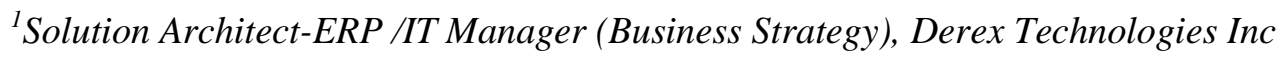

\begin{abstract}
Statistical Third-party order processing enables you to convert sales orders into purchase orders in ERP and pass them on to your vendors, so that they will provide the service for your customer. That way, when a customer orders materials from you, the materials will be directly delivered from your vendor to the customer and once statistical GR is posted, dealer will be billed.
\end{abstract}

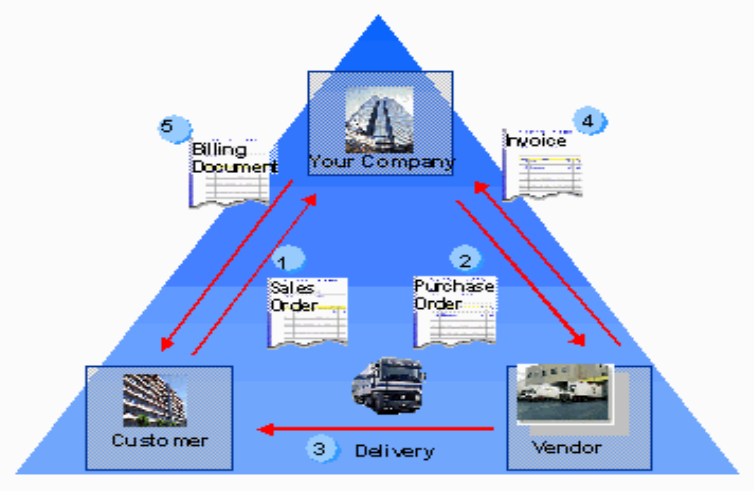

STPOP is implemented with the modules SD (Sales and Distribution) and MM (Materials Management) in automobile client. In sales orders, purchase requisitions, and purchase orders you can arrange that the vendor directly supplies your customer using what is called third-party items and statistical GR will be posted in your company. A document can consist of one or several thirdparty items.

Keywords - Statistical Third party order processing, STPOP, DS order, Third party

\section{INTRODUCTION}

In third-party order processing (also called DS or direct ship order), you can transfer responsibility of the product ordered by the customer to the supplier. Third party process supports direct shipping between a vendor/supplier and a customer. Company is not responsible for delivery of the product because you forward the purchase order to the dealer or supplier. The latter then sends the goods directly to the customer.

Direct ship represents a particular logistics process used for parts that are always ordered by the dealer/customer with the intent that the material ordered will be delivered by an outside vendor directly to the dealer/customer.

Whenever customer place the order for third party material, system determines if order is third party order or not . when sales order is saved, system automatically create the purchase requisition, with reference to this PR PO is created, this PO will send to vendor, vendor directly deliver the goods to company, then vendor raise the invoice to company for customer order and based on vendor invoice quantity,company raise the invoice to the customer, this is the process of third party processing

In other words, parts can be shipped from an external supplier to the dealer rather than from an internal warehouse. The advantage of this is that you do not need to provide intermediate storage space for goods. A sales order can consist entirely or only partly of third-party items. From time to time, you may also wish to process certain items, which you would normally deliver yourself, as third-party items.

\section{RESEARCH OBJECTIVE}

Researchers have tried to find best usability of StatisticalThird party order processing (STPOP) over 'Third Party order processing' (TPOP),by implementing both solutions in automobile client. Researchers also tried to find in which scenarios both processes i.e. TPOP and STPOP can be implemented. 


\section{BACKGROUND}

\subsection{Third Party Order Processing}

In third-party order processing (also called DS or direct ship order), you can transfer responsibility of the product ordered by the customer to the supplier. Third party process supports direct shipping between a vendor/supplier and a customer. Company is not responsible for delivery of the product because you forward the purchase order to the dealer or supplier. The latter then sends the goods directly to the customer.

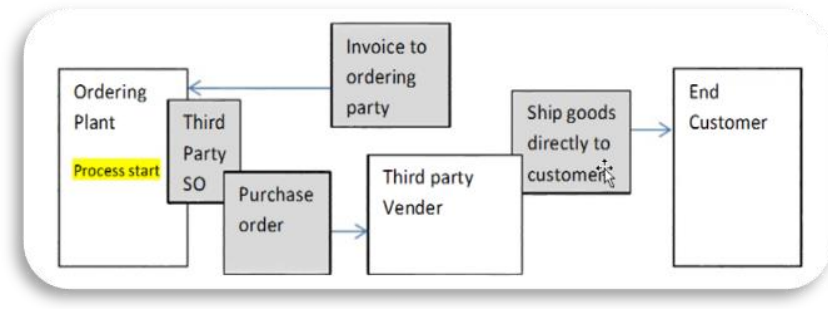

Fig 1: Sample Third Party Order processing diag

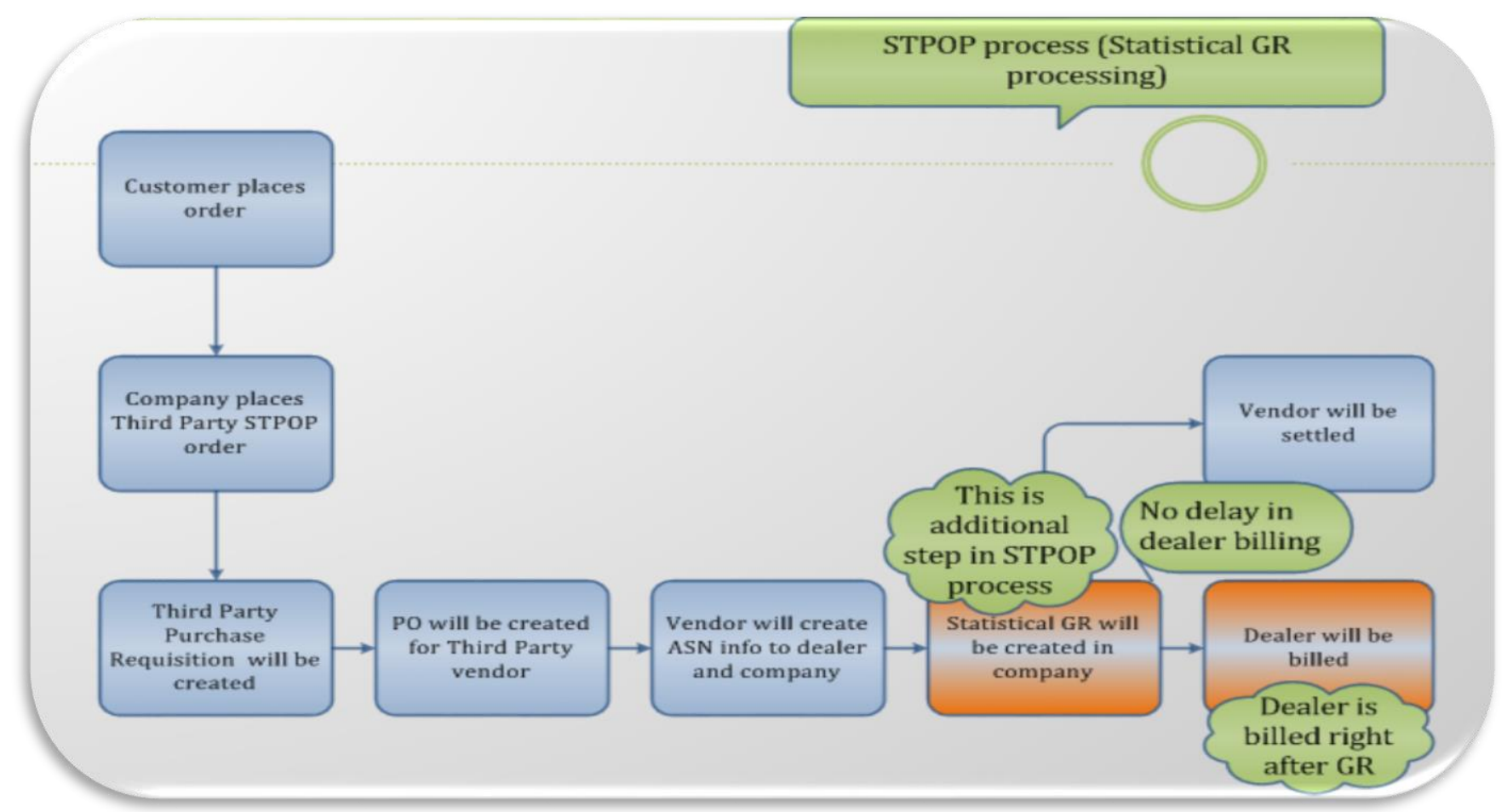

Fig 2: Sample Third Party Order processing diagram

\section{Case Study}

A case study was conducted on an automobile company in USA specialized in Trucks manufacturing. Their work encompass great amount of 'Direct ship orders' where parts are delivered directly to customers. Company was facing financial issues with their DS process. Some of majors issues which company was facing due to 'DS processes are outlined below.

\subsection{The Statistical Third Party Order Processing}

Statistical Third-party order processing (for direct-tocustomer delivery/drop shipment) is similar to 'Third Party order processing, but there is additional statistical GR will be created after ASN is received from supplier. As the name implies "Statistical ', GR will be created just for information purpose and inventory will not be bumped up in this case. Dealers / customers will be billed right after GR and company will not wait for vendor invoice to post customer's invoice. Rest of processes are almost similar to Third Party Order processing. 
within 1 year of time, dealer invoices are waived off due to "Time delay".

- No Tracking -Company is not aware of shipment details when dealers received the parts from supplier.

- Company is bypassed-in most cases, dealers bypass 'company' and directly deal with suppliers. Resulting company loses control over dealer's transactions.

\section{OUR PROPOSED METHODOLOGY}

We proposed implementing 'Statistical third party order processing' and with one year of project work, all outlined issues were addressed. Depiction of flow which was implemented in automobile client is below.

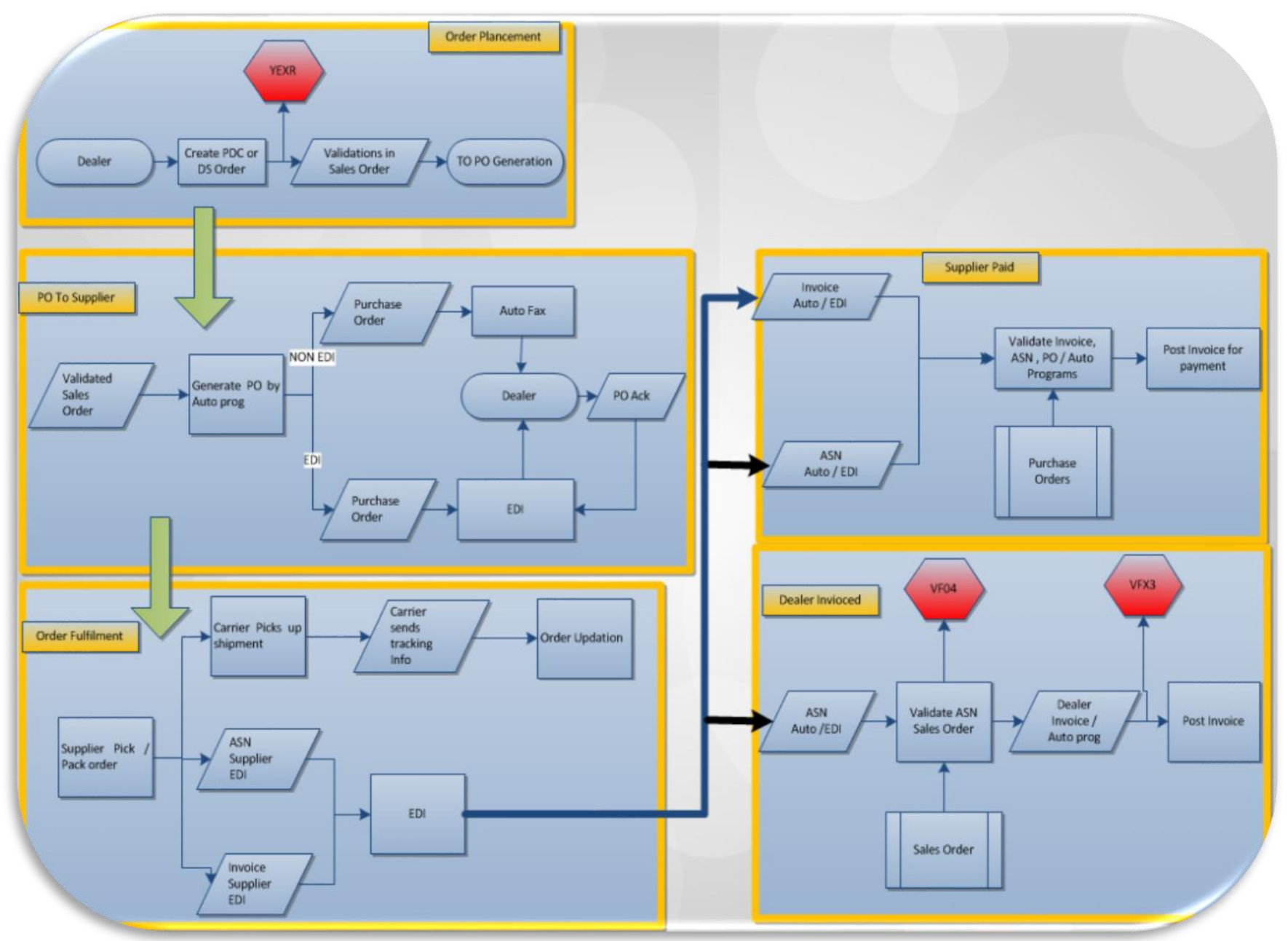

Fig 3: Statistical Third Party process flow

\subsection{Steps Involved in 'Statistical Third Party Order}

Processing'

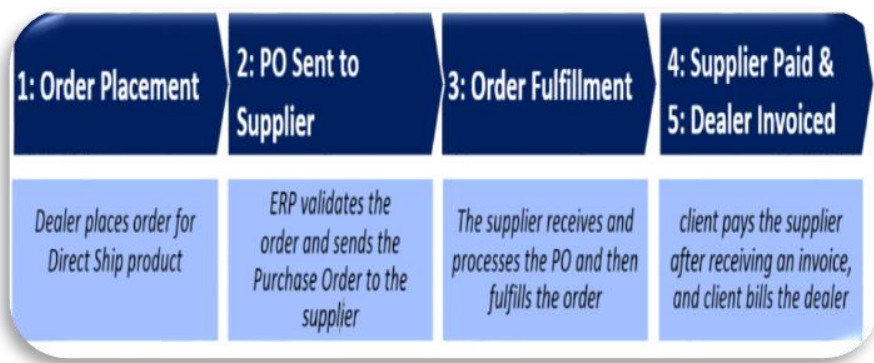

Fig 4: Steps involved in STPOP process.

\subsubsection{Step 1- STPOP-Order Placement}

Orders can be created without changes similar to TPOP processing.

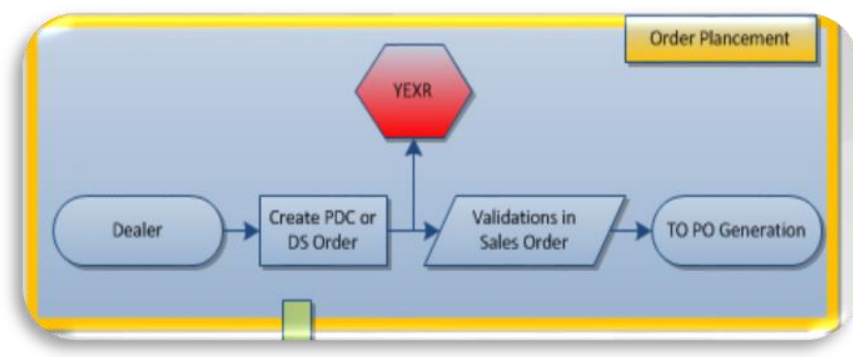

Fig 5: Order Creation in STOP process. 


\subsubsection{Step2- PO Sent to Supplier}

- Purchase Requisition Creation

ERP system should validate the STPOP order and if no issue found,Purchase requisition should be created. After the sales document has been saved, the system creates automatically a purchase requisition. The system also assigns the corresponding vendor to the purchase requisition based on the information in the purchasing information record for this part. The requisition number is visible in the sales document and can be accessed easily out of the sales document by internal users. The purchase requisition is assigned to the customer order number.

\section{- Creation of Purchase Order}

The purchase order is created based on the purchase requisition. The creation of purchase orders can be done automatically by a batch job program. The purchase order is also visible in the document flow of the sales order. The procurement document can be printed out, transferred electronically or faxed to the supplier.

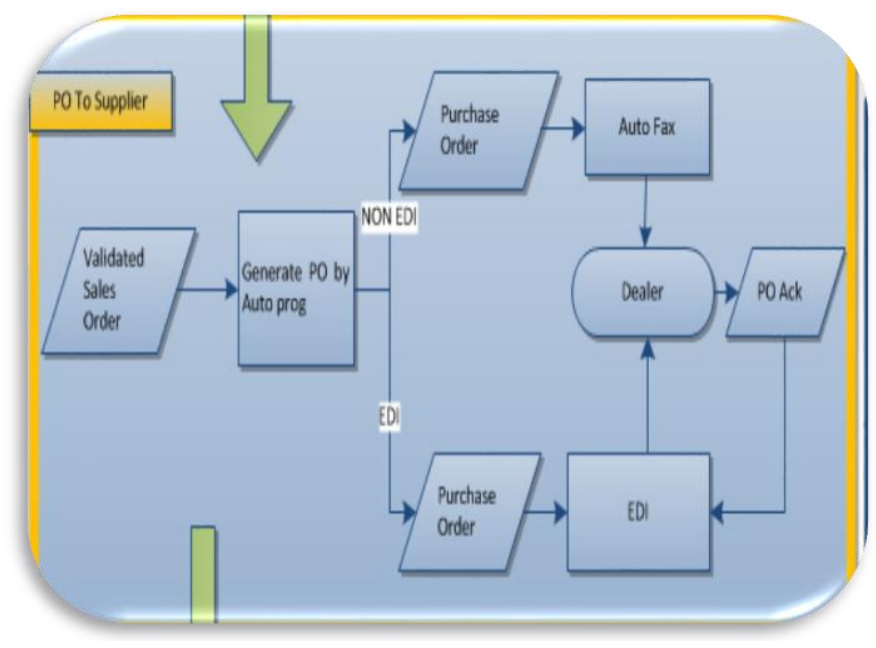

Fig 6: PO Trigger to Supplier

\subsubsection{Step 3 -Order Fulfillment}

- Order Acknowledgement from the Vendor

Order acknowledgement from the vendor (based on receiving an EDI 855) can be used to update Purchase orders dates and quantities in the PO delivery schedule item view which automatically updates the schedule line item view of the dealer order for his information. Order should be sent to supplier with dealer information. There will be statistical GR creation happen in ERP system off of ASN, statistical GR means, there will be GR documents created, but inventory will not bump up. This step is just for information purpose. Statistical GR can be used for tracking and analytical reporting purpose.

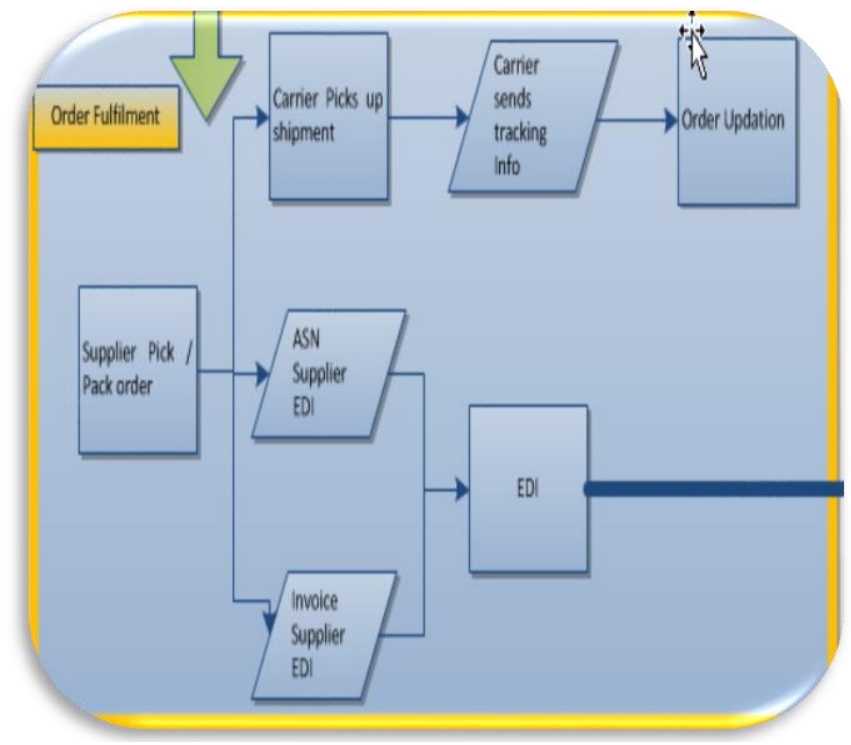

Fig 7: Order Fulfilment from Supplier

\subsubsection{Step 4 -Supplier Paid and Dealer Paid}

Once Statistical GR is created in system, ERP system will bill the dealers based on statistical GR. The dealer order, the purchase order, and the dealer invoice can be tracked in the Document Flow which can be accessed through the sales order. From the Document Flow, the user can jump into the different documents to see details.

The vendor invoice should be received and processed electronically. However, the system will also support the manual entry of the vendor invoice. The vendor invoice is then checked against the purchase order in SAP. Important data to receive for the invoice verification is:

- Vendor code

- Dealer code

- Purchase order number and item number.

- Material codes

- Quantities and prices per unit. 


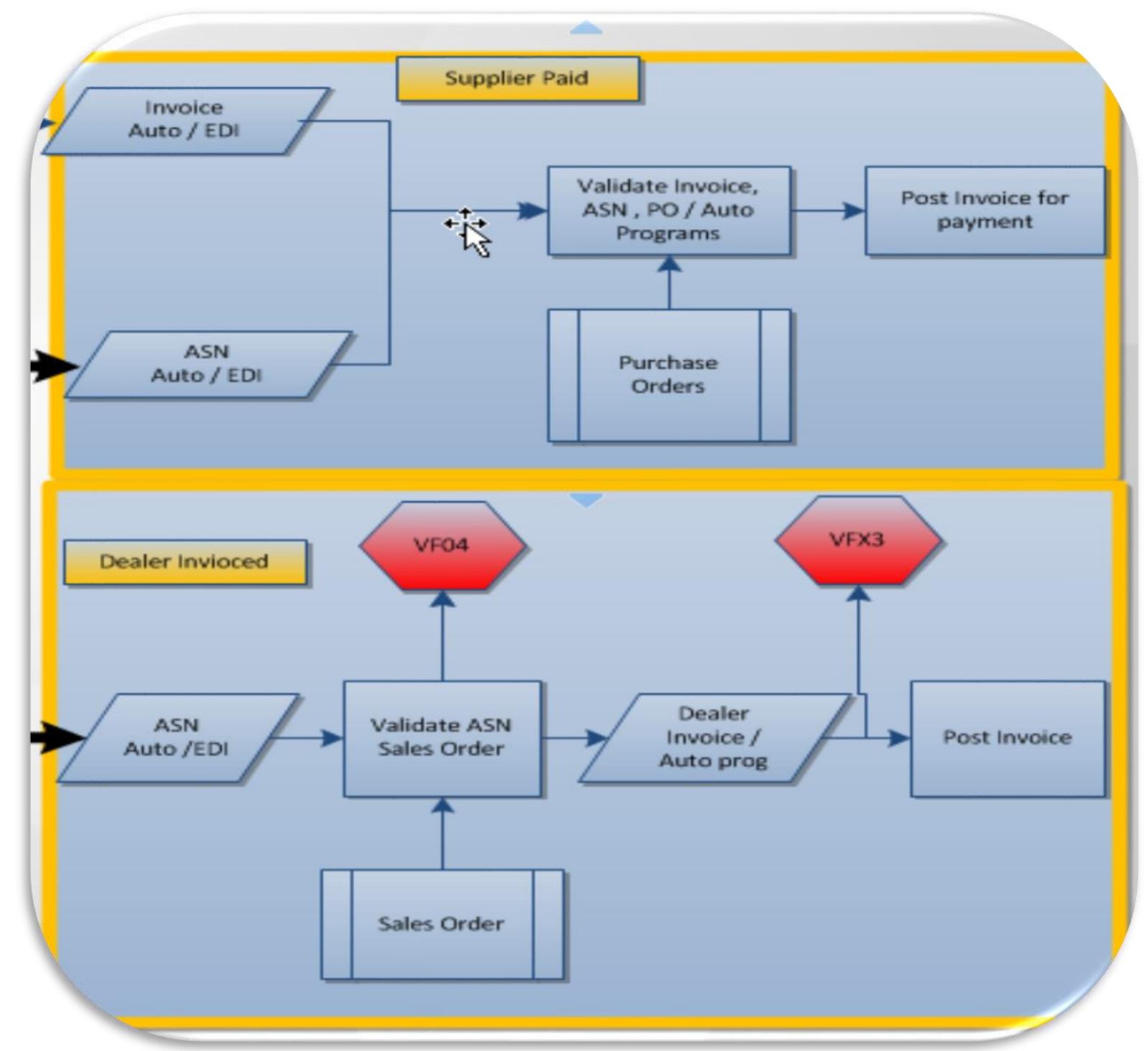

Fig 8: Supplier and Dealer Paid 


\section{PROCESS FLOW OF STPOP IMPLEMENTED IN AUTOMOBILE INDUSTRY}

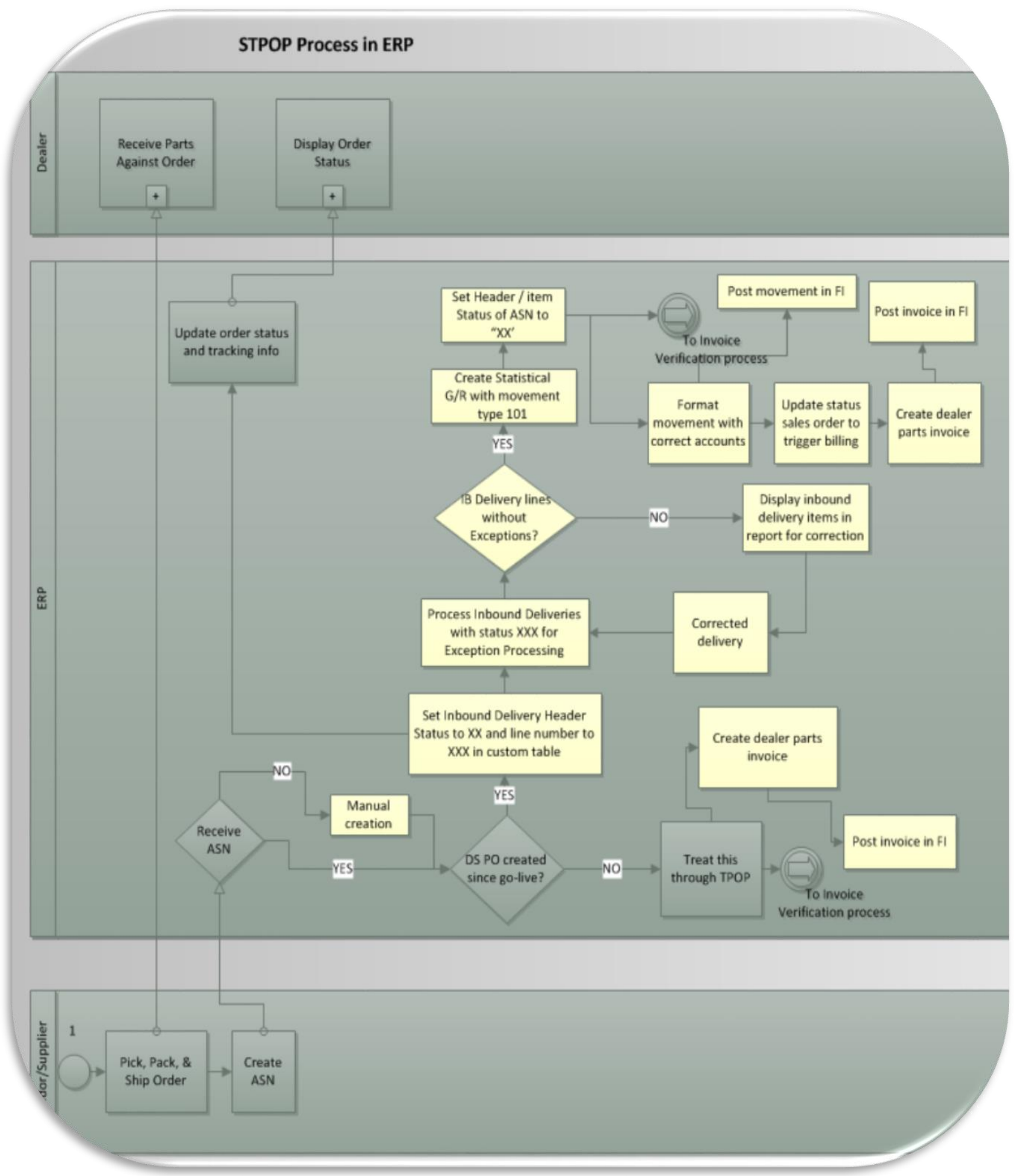

Fig 9: Process flow implemented in automobile industry

\section{RESULT}

Our research was well appreciated by both the users as wellas the management of the company who felt that the models were easy to understand and reflected the company's business objective. However biggest concern was to handle supplier POS which were created before new STPOP process implementation. To handle that, we introduced custom status on ASN creation. With this functionality, all orders created prior to STPOP handled in old way and new orders crated after STPOP functionality went through new way. 


\section{TECHNICAL CHANGES REQUIRED FOR}

\section{ACTIVATION OF STPOP}

Depending on business practice we have to implement below technical changes in company to activate STPOP process

- 'Item category' in STPOP process is TAS or TAB which is an activation of third party order processing in customer order.

- The account assignment category should be activated for 'GR' Flag. This GR activation will help in creation of third party statistical GR.

- Copy control from Sales order to billing should be modified to select, Qty from statistical GR.

- Copy control from sales order to billing should be updated to deactivate Qty copy from vendor invoice.

- Billing relevance indicator in 'Item Category' will be modified from ' $F$ ' to ' $B$ ', which means, orders will be updated in billing due list right after order creation.

- User exit in 'VF04' will be updated to accommodate sales orders.

- User exit for inbound delivery will be updated to handle statistical GR creation.

\section{CONCLUSION}

In this paper we have provided a process to implement STPOP over TPOP, and by implementing STPOP process, company can achieved below outlined benefits. If company is not concerted to monitor or track supplier consignment or if company finance department is ok in receiving dealer money with delay, due to vendor settlement, TPOP is recommended, but if company wants to track shipment and trigger dealer payment right after GR, STPOP is recommended.

- Statistical GR can be used for tracking purposes.

- Vendors Invoice and Dealer invoice can be decoupled

- Dealers can be billed right after statistical GR creation

- No Delay in dealers invoice creation.

- No Financial loss.

- Company can track parts movement though statistical GR creation.

- Better reporting for tracking.

- PO history will be updated with GR documentation.

- Suppliers invoice is independent of dealer invoice

\section{REFERENCES}

[1] Implementing SAP ERP Sales \& Distribution by Glynn C. Williams (2008). Referred Third party order processing.

[2] https://wiki.scn.sap.com/—Functional Requirements in Third Party order processing.

[3] Automobiles business practice documents 